\title{
Combustion of a coal char particle in a stream of dry gas
}

\author{
F.J. Higuera \\ E.T.S. Ingenieros Aeronáuticos, UPM, Pza. Cardenal Cisneros 3, 28040 Madrid, Spain
}

\begin{abstract}
The burning rate, surface temperature, drag, and extinction conditions of a single char particle moving in a gas are computed numerically. The effects of the size and velocity of the particle and of the temperature and composition of the gas are examined in the framework of a simple model that includes $\mathrm{O}_{2}$ and $\mathrm{CO}_{2}$ heterogeneous reactions and, in some cases, a diffusion-controlled $\mathrm{CO}$ oxidation flame in the gas around the particle. In agreement with known results, the burning rate is found to increase with the velocity of the particle when the Reynolds number of the gas flow ceases to be small. The temperature of the particle increases with the temperature and oxygen mass fraction of the gas and is little affected by the size and velocity of the particle, except in the vicinity of extinction. The drag coefficient is a decreasing function of the particle size and velocity in the range of Reynolds numbers that has been analyzed. The presence of $\mathrm{CO}_{2}$ in the gas may have an important effect on the gasification of small particles.
\end{abstract}

\section{Introduction}

Global kinetic models have been extensively used to study the combustion of coal char particles Recent semiglobal intrinsic models account for effects such as char deactivation due to thermal annealing and ash inhibition and heterogeneities in both reactivity and density of the particles, but critical reviews make clear that these models are intended to reproduce only major features of the kinetic data without directly describing the complexities of real processes, such as buildup and migration of surface oxides, inorganic catalysis, or the heterogeneities of surface sites, on which, however, they rely. As a consequence, the kinetic parameters contained in the models must be determined experimentally.

In the case of pulverized coal combustion, in particular at the high temperatures and oxygen concentrations found when mixtures of oxygen and recirculated flue gas are used, drop tube furnaces and entrained flow reactors are the most suitable facilities to reproduce in a controlled manner the conditions of the particles in practical systems. Accounts of two recent experiments of this type, with references to previous work, can be found It is not straightforward to extract kinetic parameters from the measurements of particle size and temperature histories usually obtained in these experiments, because the time evolution of the particles depends not only on the assumed kinetic model but also on the rates of heat and mass exchange with the gas, the variation of the gas conditions along the reactor, radiation, 
the combustion mode (evolution of the mean density and diameter of the particles), and the unavoidable particle-to-particle variations of size and reactivity, all of which must be accurately modeled to obtain meaningful results.

Millimeter-sized coal particles are used in furnaces such as spreader stokers, in coal gasifiers, and in fluidized bed combustion in particular with the recent pressurized combustion technology. Measurements of the devolatilization and char burn times of large captive coal particles in a quiescent gas were carried out by Essenhigh who also summarized results from other investigators Less information is available on the combustion of millimetersized particles than on pulverized coal particles, but generally these large particles burn more closely as shrinking spheres than as constant diameter particles, and diffusion rather than chemical kinetics controls the burning rate, though external diffusion alone does not fully explain the burn time data . Ragland and Yang reported mass versus time data for captive millimeter-sized coal particles as a function of gas temperature, gas velocity, oxygen concentration, particle size, and coal type. These authors find that the char burning rate normalized by the initial mass of the particle is insensitive to gas temperature in the range from 900 to $1200 \mathrm{~K}$, increases slightly with gas velocity and markedly with oxygen concentration, and decreases with particle size.

The motion of the particles relative to the gas always has an important effect on the heat and mass transfer and on the burning rate of millimeter-sized particles, and it may also have a noticeable effect for pulverized particles immersed in less gentle flows than those found in entrained flow reactors. A suite of correlations giving the Nusselt number as a function of the Reynolds and Prandtl numbers (or the Sherwood number as a function of the Reynolds and Schmidt numbers) has been used in the literature to try to account for the effect of the particle motion in a simple approximate manner: view.

More direct attempts at analyzing the flow of the gas include the work of Matsui and co-workers who experimentally studied the combustion of a heated carbon plate subjected to a stagnation point flow of air. They determined the activation energy of the heterogeneous carbon oxidation reaction, which is diffusion-controlled at high plate temperatures. Subsequently, these authors considered the effect on the burning rate of the oxidation of $\mathrm{CO}$ in the gas phase, which interferes with the heterogeneous reaction through the consumption of $\mathrm{O}_{2}$ and is affected by the presence of water vapor in the air. Adomeit and co-workers numerically solved the stagnation point flow problem and were able to match Matsui's data by taking into account the heterogeneous reactions of $\mathrm{O}_{2}$ and $\mathrm{CO}_{2}$ with $\mathrm{C}$ and different approximations to the gas-phase kinetics, which include frozen flow, equilibrium flow, an 18-reaction scheme for the oxidation of $\mathrm{CO}$, and the simple rate expression proposed by Howard et al. for this process.

Blake and Libby extended their previous analyses of the combustion of a carbon particle in a quiescent oxidizing atmosphere to the case of a slow viscosity-dominated flow of gas relative to the particle. Their formulation accounts for the heterogeneous oxidation of the carbon to $\mathrm{CO}$ and includes both frozen and flame sheet models of the gas-phase reactions. The burning rate is found to increase due to the relative motion of the gas and the particle. Monazam and Maloney measured the shape and the ratio of drag coefficient to mass of an electrically charged particle suspended in a charge trap and used Stokes' law with factors that depend on the shape of the particle to infer the particle's mass and density.

Musarra et al. used numerical computations to study the devolatilization and char oxidation of a single particle of pulverized coal in a stream of gas. They assumed a creeping flow and a constant gas density to simplify the computations; used two competing reactions to model pyrolysis, with subsequent oxidation of the pyrolysis products to $\mathrm{CO}_{2}$ and $\mathrm{H}_{2} \mathrm{O}$; and included the heterogeneous reactions (1a) and (1b) below, with rates given by Field and Mon and Amundson Their numerical results show a broad reaction region during the combustion of the volatile matter and little effect of the oxidation of $\mathrm{CO}$ during the char gasification period. Ha and Choi computed the flow around single burning char particles of diameter 100 and $150 \mu \mathrm{m}$ initially at rest in a uniform gas stream for free-stream oxygen mass fractions of $0.1,0.2$, and 0.3 and various gas velocities, leading to Reynolds numbers up to 26.1. Using a particle momentum equation with an approximate drag coefficient instead of the drag coefficient that could be computed from their numerical results, these authors found that a free particle adapts its velocity to that of the gas in a time shorter than the combustion time of the particle.

The purpose of this paper is to extend the analysis of the effect of the flow due to the motion of a burning char particle, removing some of the simplifying assumptions that have been made in previous works and covering a larger range of particle sizes and gas conditions. A simple kinetic model devoid of the sophistication commented on above will be used to clearly bring out the effect of the flow. The influences of the size and velocity of the particle and of the temperature and composition of the gas on the burning rate, the particle temperature, the extinction of the heterogeneous reactions, and the drag of the particle 
are examined both for a large particle surrounded by a CO oxidation flame and for a small particle undergoing $\mathrm{O}_{2}$ and $\mathrm{CO}_{2}$ heterogeneous reactions only.

\section{Formulation}

The following simple model is used in what follows to study the effect of the motion of a single burning char particle relative to the surrounding gas. The heterogeneous reactions

$\mathrm{C}+\frac{1}{2} \mathrm{O}_{2} \rightarrow \mathrm{CO}$

$\mathrm{C}+\mathrm{CO}_{2} \rightarrow 2 \mathrm{CO}$,

are taken into account at the surface of the particle, and the gas-phase reaction

$\mathrm{CO}+\frac{1}{2} \mathrm{O}_{2} \rightarrow \mathrm{CO}_{2}$

is assumed to occur in cases where $\mathrm{CO}$ oxidation takes place in a diffusion flame around the particle. The rates of the heterogeneous reactions (mass of carbon consumed per unit surface area and per unit time) are

$\tilde{m}_{1}=B_{1} e^{-E_{1} / R T_{\mathrm{s}}}\left(\rho Y_{\mathrm{O}_{2}}\right)^{n_{1}}$,

$\tilde{m}_{2}=B_{2} e^{-E_{2} / R T_{\mathrm{s}}}\left(\rho Y_{\mathrm{CO}_{2}}\right)^{n_{2}}$,

where $T_{\mathrm{S}}$ is the particle surface temperature and $\rho$, $Y_{\mathrm{O}_{2}}$, and $Y_{\mathrm{CO}_{2}}$ are the density and mass fractions of oxygen and carbon dioxide of the gas at the surface. The model assumes a shrinking-sphere combustion mode with no heterogeneous reaction inside the particle. The porosity of the particle is taken into account only to the extent that its effect can be included in effective values of the pre-exponential factors $B_{1}$ and $B_{2}$, the activation energies $E_{1}$ and $E_{2}$, and the reaction orders $n_{1}$ and $n_{2}$. The gas-phase reaction is assumed to be infinitely fast when it occurs. No attempt is made to determine the precise conditions under which a CO oxidation flame surrounds the particle. This would require a detailed analysis of the ignition and extinction of the gas flame, whose real kinetics is known to be complex and much dependent on the presence of water vapor in the gas.

The flow of the gas is quasi-stationary because the combustion time of the particle is always large compared with the residence and diffusion times of the gas. The particle will be assumed to be spherical and the gas flow axisymmetric. This flow is computed by solving the mass, momentum, energy, and species conservation equations in the quasi-isobaric low-Mach-number approximation, in which pressure variations appear only in the momentum equation. In what follows distances are scaled with the radius of the particle, $a$, the gas velocity, density, and temperature are scaled with their values in the free stream far from the particle, $U_{\infty}, \rho_{\infty}$, and $T_{\infty}$, respectively, and the mass fractions of all the species are scaled with the mass fraction of oxygen in the free stream, $Y_{\mathrm{O}_{2} \infty}$. In the absence of gas-phase reactions, the dimensionless conservation equations are

$$
\begin{aligned}
& \nabla \cdot(\rho \mathbf{v})=0, \\
& \rho \mathbf{v} \cdot \nabla \mathbf{v}=-\nabla p+\frac{1}{\operatorname{Re}} \nabla \cdot \tau^{\prime}, \\
& \rho T=1, \\
& \rho \mathbf{v} \cdot \nabla T=\frac{1}{\operatorname{RePr}} \nabla \cdot(k \nabla T), \\
& \rho \mathbf{v} \cdot \nabla Y_{i}=\frac{1}{\operatorname{ReSc}_{i}} \nabla \cdot\left(\rho D_{i} \nabla Y_{i}\right),
\end{aligned}
$$

where $i=\mathrm{O}_{2}, \mathrm{CO}_{2}, \mathrm{CO} ; \tau^{\prime}=\mu\left[\nabla \mathbf{v}+(\nabla \mathbf{v})^{\mathrm{T}}\right]$ is the nonspherical part of the dimensionless viscous stress tensor; the spherical part of the tensor is included in the pressure, which is referred to the free stream pressure and scaled with $\rho_{\infty} U_{\infty}^{2} ; \mu, k$, and $D_{i}$ are the dimensionless gas viscosity, thermal conductivity, and mass diffusivities, scaled with their free stream values $\mu_{\infty}, k_{\infty}$, and $D_{i \infty}$; and $\operatorname{Re}, \operatorname{Pr}$, and $\mathrm{Sc}_{i}$ are the Reynolds, Prandtl, and Schmidt numbers,

$$
\begin{aligned}
& \operatorname{Re}=\frac{\rho_{\infty} U_{\infty} a}{\mu_{\infty}}, \\
& \operatorname{Pr}=\frac{\mu_{\infty} c_{\mathrm{p}}}{k_{\infty}}, \\
& \mathrm{Sc}_{i}=\frac{\mu_{\infty}}{\rho_{\infty} D_{i \infty}},
\end{aligned}
$$

where $c_{\mathrm{p}}$ is the specific heat of the gas at constant pressure, which is assumed to be constant. A common power law is assumed for the temperature dependence of the dimensionless transport coefficients,

$\mu=k=\rho D_{i}=T^{\lambda}$.

The variation of the mean molecular mass of the gas is neglected in (4).

When there is an infinitely thin diffusion flame in the gas around the particle, Eqs. (5) and (6) can be conveniently replaced by transport equations for the Schvab-Zeldovich variables and the condition of noncoexistence of the reactants. In the equidiffusional case $\operatorname{Pr}=\mathrm{Sc}_{i}$, these equations are

$\rho \mathbf{v} \cdot \nabla Z_{i}=\frac{1}{\operatorname{RePr}} \nabla \cdot\left(k \nabla Z_{i}\right)$

for $i=\mathrm{CO}, \mathrm{CO}_{2}, \mathrm{~T}$, and

$Y_{\mathrm{O}_{2}} Y_{\mathrm{CO}}=0$,

where

$Z_{\mathrm{CO}}=Y_{\mathrm{CO}}-v_{\mathrm{g}_{\mathrm{CO}}}\left(Y_{\mathrm{O}_{2}}-1\right)$,

$Z_{\mathrm{CO}_{2}}=Y_{\mathrm{CO}_{2}}+v_{\mathrm{g}_{2}}\left(Y_{\mathrm{O}_{2}}-1\right)$,

$Z_{\mathrm{T}}=T+\gamma_{3}\left(Y_{\mathrm{O}_{2}}-1\right)$. 
Here $v_{\mathrm{g}_{\mathrm{CO}}}=M_{\mathrm{CO}} /\left(M_{\mathrm{O}_{2}} / 2\right)=7 / 4, v_{\mathrm{g}_{\mathrm{CO}}}=M_{\mathrm{CO}_{2}} /$ $\left(M_{\mathrm{O}_{2}} / 2\right)=11 / 4$, and $\gamma_{3}=v_{\mathrm{g} C O} q_{3} Y_{\mathrm{O}_{2} \infty} / c_{\mathrm{p}} T_{\infty}$, where $M_{i}$ are the molecular masses of the different species and $q_{3}$ is the heat released by the gasphase reaction per unit mass of $\mathrm{CO}$ consumed. The flame sheet, where $Y_{\mathrm{O}_{2}}=Y_{\mathrm{CO}}=0$, is the contour $Z_{\mathrm{CO}}=v_{\mathrm{g}_{\mathrm{CO}}}$, which is determined as part of the solution of the problem. The CO flame coincides with the surface of the particle when $Z_{\mathrm{CO}}<v_{\mathrm{g}_{\mathrm{CO}}}$ everywhere in the gas. Then Eqs. (9) revert to the forms (5) and (6) for an inert gas, and the effect of the CO oxidation appears in the boundary conditions at the surface of the particle (Eqs. (21)-(23) below).

When only the heterogeneous reactions (1a) and (1b) occur at the surface, the boundary conditions to be satisfied at $|\mathrm{x}|=1$ are

$$
\begin{aligned}
& \rho \mathbf{v} \cdot \mathbf{n}=m, \quad \mathbf{v} \times \mathbf{n}=0, \quad T=T_{\mathrm{s}}, \\
& m Y_{\mathrm{O}_{2}}-\frac{1}{\operatorname{ReS\mathrm {O}_{2}}} \rho D_{\mathrm{O}_{2}} \mathbf{n} \cdot \nabla Y_{\mathrm{O}_{2}}=-S_{\mathrm{O}_{2}} m_{1}, \\
& m Y_{\mathrm{CO}_{2}}-\frac{1}{\operatorname{ReSc} \mathrm{CO}_{2}} \rho D_{\mathrm{CO}_{2}} \mathbf{n} \cdot \nabla Y_{\mathrm{CO}_{2}} \\
& \quad=-S_{\mathrm{CO}_{2}} m_{2}, \\
& m Y_{\mathrm{CO}}-\frac{1}{\operatorname{ReSc}} \rho D_{\mathrm{CO}} \mathbf{n} \cdot \nabla Y_{\mathrm{CO}} \\
& \quad=S_{(\mathrm{CO})_{1}} m_{1}+S_{(\mathrm{CO})_{2}} m_{2}, \\
& m T-\frac{1}{\operatorname{RePr} \operatorname{Pr}} k \nabla T+q_{\mathrm{s}}=\gamma_{1} m_{1}+\gamma_{2} m_{2},
\end{aligned}
$$

where $\mathbf{n}$ is a unit vector normal to the surface and pointing toward the gas; $T_{\mathrm{S}}$ is the temperature of the surface; $S_{\mathrm{O}_{2}}=v_{\mathrm{O}_{2}} / Y_{\mathrm{O}_{2} \infty}, S_{\mathrm{CO}_{2}}=$ $v_{\mathrm{CO}_{2}} / Y_{\mathrm{O}_{2} \infty}, S_{(\mathrm{CO})_{1}}=v_{(\mathrm{CO})_{1}} / Y_{\mathrm{O}_{2} \infty}$, and $S_{(\mathrm{CO})_{2}}=$ $v_{(\mathrm{CO})_{2}} / Y_{\mathrm{O}_{2} \infty}$, with $v_{\mathrm{O}_{2}}=\left(M_{\mathrm{O}_{2}} / 2\right) / M_{\mathrm{C}}=4 / 3$, $v_{\mathrm{CO}_{2}}=M_{\mathrm{CO}_{2}} / M_{\mathrm{C}}=11 / 3, v_{(\mathrm{CO})_{1}}=M_{\mathrm{CO}} / M_{\mathrm{C}}=$ $7 / 3$, and $v_{(\mathrm{CO})_{2}}=2 M_{\mathrm{CO}} / M_{\mathrm{C}}=14 / 3$ are stoichiometric factors, and

$$
\left.\begin{array}{l}
m_{1}=\frac{\tilde{m}_{1}}{\rho_{\infty} U_{\infty}}=\mathrm{Da}_{1} e^{-T_{\mathrm{a}_{1}} / T_{\mathrm{s}}}\left(\rho Y_{\mathrm{O}_{2}}\right)^{n_{1}}, \\
m_{2}=\frac{\widetilde{m}_{2}}{\rho_{\infty} U_{\infty}}=\mathrm{Da}_{2} e^{-T_{\mathrm{a}_{2}} / T_{\mathrm{s}}}\left(\rho Y_{\mathrm{CO}_{2}}\right)^{n_{2}}, \\
m=m_{1}+m_{2},
\end{array}\right\}
$$

with the Damköhler numbers

$$
\begin{aligned}
& \mathrm{Da}_{1}=\frac{B_{1} Y_{\mathrm{O}_{2} \infty}^{n_{1}}}{\rho_{\infty}^{1-n_{1}} U_{\infty}}, \\
& \mathrm{Da}_{2}=\frac{B_{2} Y_{\mathrm{O}_{2} \infty}^{n_{2}}}{\rho_{\infty}^{1-n_{2}} U_{\infty}},
\end{aligned}
$$

and the dimensionless activation temperatures $T_{\mathrm{a}_{1}}=$ $E_{1} / R T_{\infty}$ and $T_{\mathrm{a}_{2}}=E_{2} / R T_{\infty}$. In the energy balance (16), $q_{\mathrm{s}}$ is the dimensionless heat flux entering the solid (scaled with $\rho_{\infty} U_{\infty} c_{\mathrm{p}} T_{\infty}$ ) and the parame- ters on the right-hand side are $\gamma_{1}=q_{1} / c_{\mathrm{p}} T_{\infty}$ and $\gamma_{2}=q_{2} / c_{\mathrm{p}} T_{\infty}$, where $q_{1}$ and $q_{2}$ are the heats released by the heterogeneous reactions (1a) and (1b) per unit mass of carbon consumed $\left(q_{2}<0\right.$ for the endothermic reaction (1b)).

Radiative transfer between the particle and its surroundings has not been included in the energy balance (16), which is a significant idealization to be kept in mind when interpreting the results of the paper. Radiative boundary conditions are different for every practical application of a burning char particle, which makes it difficult to account for the effect of radiation in a general analysis.

When there is a diffusion flame in the gas, the mass fraction of oxygen is zero between the flame and the surface, so that reaction (1a) does not occur, and the boundary conditions for the Schvab-Zeldovich variables at the surface are

$$
\begin{aligned}
& m_{2} Z_{\mathrm{CO}}-\frac{1}{\operatorname{RePr}} k \mathbf{n} \cdot \nabla Z_{\mathrm{CO}} \\
& \quad=\left(S_{(\mathrm{CO})_{2}}+v_{\mathrm{g}_{\mathrm{CO}}}\right) m_{2}, \\
& m_{2} Z_{\mathrm{CO}_{2}}-\frac{1}{\operatorname{RePr}} k \mathbf{n} \cdot \nabla Z_{\mathrm{CO}_{2}} \\
& \quad=-\left(S_{\mathrm{CO}_{2}}+v_{\mathrm{g}_{\mathrm{CO}_{2}}}\right) m_{2}, \\
& m_{2} Z_{\mathrm{T}}-\frac{1}{\operatorname{RePr}} k \mathbf{n} \cdot \nabla Z_{\mathrm{T}}+q_{\mathrm{s}}=\left(\gamma_{2}-\gamma_{3}\right) m_{2},
\end{aligned}
$$

in the equidiffusional case.

When the diffusion flame coincides with the surface of the particle, the effective surface reactions are

$$
\begin{aligned}
& \text { (1a) }+(1 \mathrm{c}): \mathrm{C}+\mathrm{O}_{2} \rightarrow \mathrm{CO}_{2}, \\
& (1 \mathrm{~b})+2 \times(1 \mathrm{c}): \mathrm{C}+\mathrm{O}_{2} \rightarrow \mathrm{CO}_{2},
\end{aligned}
$$

with the rates (17) of (1a) and (1b), respectively. No carbon monoxide is left in the gas, and the balances (13), (14), and (16) at the surface change to

$$
\begin{aligned}
& m Y_{\mathrm{O}_{2}}-\frac{1}{\operatorname{RePr}} k \mathbf{n} \cdot \nabla Y_{\mathrm{O}_{2}}=-2 S_{\mathrm{O}_{2}} m, \\
& m Y_{\mathrm{CO}_{2}}-\frac{1}{\operatorname{Re} \operatorname{Pr}} k \mathbf{n} \cdot \nabla Y_{\mathrm{CO}_{2}}=S_{\mathrm{CO}_{2}} m, \\
& m T-\frac{1}{\operatorname{RePr}} k \mathbf{n} \cdot \nabla T+q_{\mathrm{s}} \\
& \quad=\left(\gamma_{1}+\frac{S_{(\mathrm{CO})_{1}}}{v_{\mathrm{g}_{\mathrm{CO}}}} \gamma_{3}\right) m_{1}+\left(\gamma_{2}+\frac{S_{(\mathrm{CO})_{2}}}{\nu_{\mathrm{g}_{\mathrm{CO}}}} \gamma_{3}\right) m_{2} .
\end{aligned}
$$

The boundary conditions at the free stream far from the particle $(\mathbf{x} \rightarrow \infty)$ are

$$
\left.\begin{array}{l}
\mathbf{v}=\mathbf{i}, \quad p=0, \quad T=1, \\
Y_{\mathrm{O}_{2}}=1, \quad Y_{\mathrm{CO}_{2}}=Y_{1}, \quad Y_{\mathrm{CO}}=Y_{2},
\end{array}\right\}
$$

where $\mathbf{i}$ is a unit vector in the direction of the free stream, and $Y_{1}=Y_{\mathrm{CO}_{2} \infty} / Y_{\mathrm{O}_{2} \infty}$ and $Y_{2}=$ $Y_{\mathrm{CO} \infty} / Y_{\mathrm{O}_{2} \infty}$ are the free stream mass fractions of 
$\mathrm{CO}_{2}$ and $\mathrm{CO}$ scaled with the free stream mass fraction of $\mathrm{O}_{2}$. It must be that $Y_{2}=0$ when there is a $\mathrm{CO}$ flame in the gas around the particle or adjacent to its surface.

The problem for the gas phase consists of the appropriate subset of Eqs. (2)-(24). These equations must be supplemented with a relation between the temperature of the surface, $T_{\mathrm{S}}$, and the heat flux entering the particle, $q_{\mathrm{s}}$, which appear in (12) and the energy balance at the surface, (16) or (20) or (23). The variables $T_{\mathrm{S}}$ and $q_{\mathrm{s}}$ need not be uniform on the surface, and the relation between them, which comes from the energy equation for the solid, is not local or quasi-stationary in general. If the conduction time in the solid, $t_{\mathrm{c}}=\rho_{\mathrm{S}} c_{\mathrm{s}} a^{2} / k_{\mathrm{s}}$, where $\rho_{\mathrm{S}}, c_{\mathrm{S}}$, and $k_{\mathrm{S}}$ are the solid density, specific heat, and thermal conductivity, is short compared with the lifetime of the particle and the characteristic time of variation of the ambient conditions seen by the particle, then $T_{\mathrm{S}}$ is nearly uniform except during an initial period of order $t_{\mathrm{c}}$. The gas phase problem can be solved for a given value of $T_{\mathrm{S}}$ without using the energy balance at the surface, which is used afterwards to determine the surface distribution of $q_{\mathrm{s}}$. The time evolution of $T_{\mathrm{s}}$ and the dimensionless radius of the particle, $\bar{a}=a / a_{0}$, where $a_{0}$ is the initial radius and the particle is assumed to remain spherical during the gasification process, follow then from the mass and energy equations

$$
\frac{d \bar{a}}{d \tau}=-\langle m\rangle \quad \text { and } \quad \bar{a} \frac{c_{\mathrm{s}}}{3 c_{\mathrm{p}}} \frac{d T_{\mathrm{s}}}{d \tau}=\left\langle q_{\mathrm{s}}\right\rangle,
$$

where $\tau=\left(\rho_{\infty} / \rho_{\mathrm{s}}\right)\left(U_{\infty} t / a_{0}\right)$ is a dimensionless time and $\langle m\rangle$ and $\left\langle q_{\mathrm{s}}\right\rangle$ are the surface-averaged values

$$
\langle m\rangle=\frac{1}{4 \pi} \int_{|\mathbf{x}|=1} m d \sigma \quad \text { and } \quad\left\langle q_{\mathrm{s}}\right\rangle=\frac{1}{4 \pi} \int_{|\mathbf{x}|=1} q_{\mathrm{s}} d \sigma
$$

The solution of the problem formulated in this section depends on the dimensionless parameters

$$
\left.\begin{array}{l}
\mathrm{Re}, \mathrm{Pr}, \mathrm{Sc}_{i}, \lambda, \\
\mathrm{Da}_{1}, \mathrm{Da}_{2}, T_{\mathrm{a}_{1}}, T_{\mathrm{a}_{2}}, n_{1}, n_{2}, \\
\gamma_{1}, \gamma_{2}, \gamma_{3}, \\
c_{\mathrm{S}} / c_{\mathrm{p}}, Y_{1}, Y_{2}, Y_{\mathrm{O}_{2} \infty},
\end{array}\right\}
$$

where $Y_{\mathrm{O}_{2} \infty}$ determines all the mass stoichiometric factors in the equations above.

For the numerical treatment, the conservation equations for the gas phase have been discretized using second-order finite differences and solved by means of a standard pseudo-transient iterative method. The vorticity/stream function formulation equivalent to (2) and (3) has been used.

\section{Results and discussion}

\subsection{Reference state}

The parameter values $\operatorname{Pr}=\mathrm{Sc}_{i}=1, n_{1}=n_{2}=1$, $\lambda=1 / 2$ are used in what follows. The dimensionless variables of the previous section allow a concise formulation and solution of the problem but are not convenient for comparing results for different sizes and velocities of the particle and different temperatures and compositions of the gas, because these magnitudes appear in the scaling factors. In order to simplify such comparisons, the following reference values and notation are introduced and used to rescale the numerical results:

$$
\left.\begin{array}{l}
\rho_{\infty_{\mathrm{r}}}=0.273 \mathrm{~kg} / \mathrm{m}^{3}, \quad T_{\infty_{\mathrm{r}}}=1000 \mathrm{~K}, \\
a_{\mathrm{r}}=200 \mu \mathrm{m}, \quad U_{\infty_{\mathrm{r}}}=1 \mathrm{~m} / \mathrm{s}, \\
\theta=\frac{T_{\infty}}{T_{\infty_{\mathrm{r}}}}, \quad \alpha=\frac{a}{a_{\mathrm{r}}}, \quad U=\frac{U_{\infty}}{U_{\infty \mathrm{r}}} .
\end{array}\right\}
$$

Here $\rho_{\infty_{\mathrm{r}}}$ is the density of air at temperature $T_{\infty_{\mathrm{r}}}$ and pressure $1 \mathrm{~atm}$. The Reynolds number evaluated with the reference values (28) and the viscosity of air at temperature $T_{\infty_{\mathrm{r}}}$ is equal to unity. The values of other dimensionless parameters in the reference state are $\mathrm{Da}_{1_{\mathrm{r}}}=\mathrm{Da}_{2_{\mathrm{r}}}=2.3 \times 10^{7} Y_{\mathrm{O}_{2} \infty}$, $T_{a_{1 r}}=26.2, T_{a_{2 r}}=40, \gamma_{1_{\mathrm{r}}}=9.24, \gamma_{2_{\mathrm{r}}}=-14.31$, $\gamma_{3_{\mathrm{r}}}=17.68 Y_{\mathrm{O}_{2} \infty}$. The values of these parameters at any other state at atmospheric pressure, defined by $\theta, \alpha$, and $U$, are $\operatorname{Re}=\alpha U / \theta^{3 / 2}, \mathrm{Da}_{j}=\mathrm{Da}_{j_{\mathrm{r}}} \theta / U$, $T_{a_{j}}=T_{a_{\mathrm{jr}}} / \theta$, and $\gamma_{j}=\gamma_{j_{\mathrm{r}}} / \theta$. The burning rate of the particle scaled with $\rho_{\infty_{\mathrm{r}}} U_{\infty_{\mathrm{r}}} a_{\mathrm{r}}^{2}$ is $4 \pi\langle m\rangle \alpha^{2} U / \theta$, and the surface temperature scaled with $T_{\infty_{\text {r }}}$ (i.e., in units of 1000 Kelvin) is $T_{\mathrm{S}} \theta$.

The formulation of Section 2 is valid for a quiescent particle if $\mu_{\infty} / \rho_{\infty} a$ is used as a velocity scale instead of $U_{\infty}$, which amounts to setting $\operatorname{Re}=1$ in the dimensionless governing equations, and the velocity in the boundary conditions (24) far from the particle is replaced by $\mathbf{v}=0$. When the reference values (28) are used for a quiescent particle, only $\theta$ and $\alpha$ remain as independent parameters, whereas $U=\theta^{3 / 2} / \alpha$.

\subsection{Quasi-steady gasification and combustion}

The burning rate is shown in Fig. 1 as a function of the surface temperature for $\theta=1.35\left(T_{\infty}=1350 \mathrm{~K}\right)$, $\alpha=50$ (a 10-mm particle radius), $Y_{1}=0\left(Y_{\mathrm{CO}_{2} \infty}=\right.$ 0 ), and various velocities of the flow and ambient oxygen mass fractions. Two curves are shown for each case. The smooth curve of each couple gives the burning rate in the absence of a gas-phase reaction. The curve with a kink or a dotted segment gives the burning rate when $\mathrm{CO}$ oxidation occurs in a diffusion flame in the gas around the particle or adjacent 

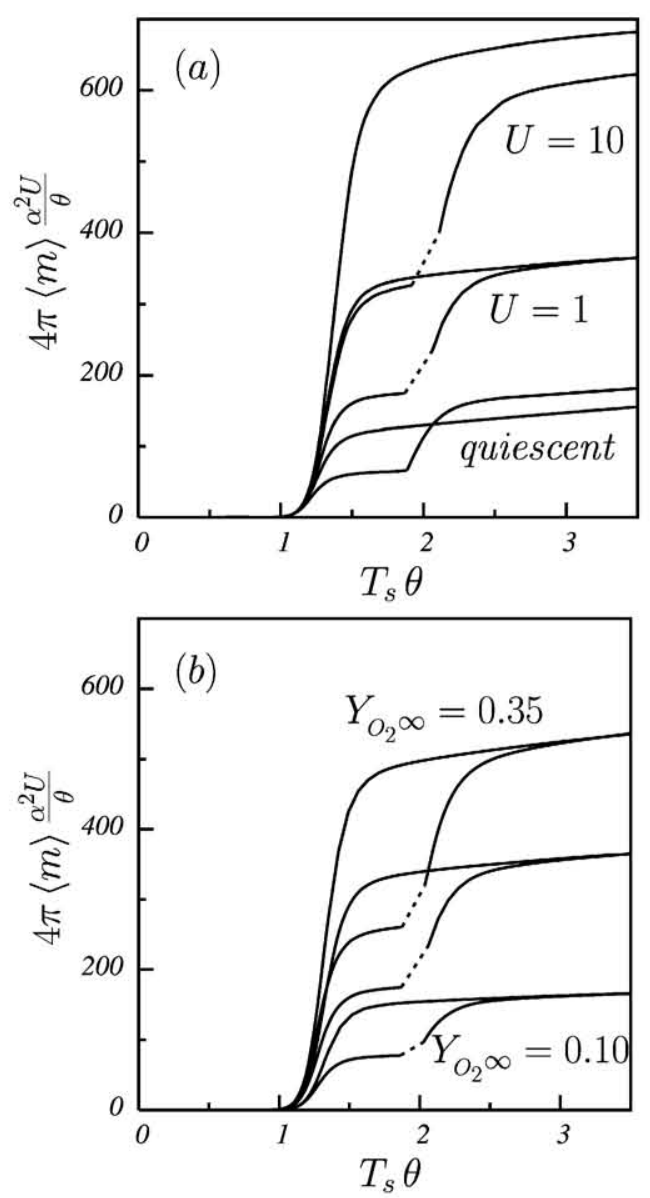

Fig. 1. Burning rate scaled with $\rho_{\infty_{\mathrm{r}}} U_{\infty_{\mathrm{r}}} a_{\mathrm{r}}^{2}=1.09 \times$ $10^{-8} \mathrm{~kg} / \mathrm{s}$ as a function of the surface temperature scaled with $T_{\infty_{\mathrm{r}}}=1000 \mathrm{~K}$ for $\theta=1.35\left(T_{\infty}=1350 \mathrm{~K}\right)$ and $\alpha=50$ (10-mm particle radius). In (a), for $Y_{\mathrm{O}_{2} \infty}=0.23$, the three couples of curves are, from bottom to top, for a quiescent particle, for $U=1\left(U_{\infty}=1 \mathrm{~m} / \mathrm{s}\right)$, and for $U=10$ $\left(U_{\infty}=10 \mathrm{~m} / \mathrm{s}\right)$. In (b), for $U=1$, the three couples of curves are for $Y_{\mathrm{O}_{2} \infty}=0.1,0.23$, and 0.35 . The upper curve of each couple gives the burning rate in the absence of a gas flame.

to its surface. The CO flame coincides with the surface in the low-temperature region of this curve and is detached from the surface in the high-temperature region. The transition between both regimes occurs at a definite surface temperature for a quiescent particle but over a range of temperatures, denoted by the dotted segments (not computed) in Fig. 1, for a moving particle. This is because the flame around a moving particle is not spherical, and detachment does not occur simultaneously over the whole surface.

The lowest couple of curves in Fig. 1a, for a quiescent particle, may be compared with the results of Blake and Libby Makino and Law and Makino The qualitative agreement is good, but the burning rate in Figs. 1-4 is always higher in the absence of gas flame, and the two curves tend to coincide when the heterogeneous reactions become diffusion-controlled. These results are consequences of the assumption that $\rho D_{i}=$ constant made in the cited works, which leads to radial profiles of the passive scalars independent of the presence and position of a gas flame. This assumption is not made here, and the two curves of each couple tend to coincide only for $T_{\mathrm{S}} \rightarrow \infty$.

The two upper couples of curves in Fig. 1a show that the burning rate increases with the velocity of the particle relative to the surrounding gas, which is due to the enhanced transfer of reactants from the gas to the particle surface. The effect of the flow is somewhat more pronounced in the absence of gas flame, and changes the relative position of the curves of each couple at the right-hand side of the figure. When a $\mathrm{CO}$ flame is present, the temperature at which it fully detaches from the surface increases slightly with the velocity of the particle. Fig. 1b shows the effect of the oxygen mass fraction $Y_{\mathrm{O}_{2} \infty}$ on the burning rate.

Global heat and mass transfer rates can be computed from the numerical solutions. The Nusselt number, equal to the surface averaged conduction flux scaled with $k_{\infty}\left(T_{\mathrm{S}}-T_{\infty}\right) /(2 a)$, is given by $\mathrm{Nu}=$ $-2\langle k \mathrm{n} \cdot \nabla T\rangle /\left(T_{\mathrm{S}}-1\right)$ in terms of the dimensionless variables of the previous section. Here, as in (26), $\langle\cdot\rangle$ means surface average. The Nusselt number is shown in Fig. 2 as a function of the dimensionless surface temperature for the same cases as in Fig. 1. The large negative values of $\mathrm{Nu}$ in Fig. 2 (notice the 10 -fold contraction of the vertical scale) are for cases with a CO flame around the particle, for which heat reaches the particle by conduction from the flame. The Nusselt numbers for cases without a CO flame and with a $\mathrm{CO}$ flame coinciding with the surface are nearly equal to each other. These Nusselt number increase only slightly with the particle temperature and markedly with its velocity. The Nusselt number for a quiescent particle is not far from the value of 2 corresponding to a gas of constant conductivity in the absence of radial gasification flow. The conductivity of the gas and the gasification rate both increase with the particle temperature, but their effects on the Nusselt number are opposite and nearly balance each other. The increase of the Nusselt number with the velocity of the particle is in reasonable agreement with the Marshall-Ranz correlation $\mathrm{Nu}=2+0.6 \operatorname{Re}^{1 / 2} \operatorname{Pr}^{1 / 3}$ which gives $\mathrm{Nu}=5.39$ and 12.71 for the cases of the two upper couples of curves of Fig. 2, for which $\operatorname{Pr}=1$ and $\operatorname{Re}=31.88$ and 318.76, respectively. Similar agreement is found for smaller particles, though the numerical results are not included in Fig. 2. 


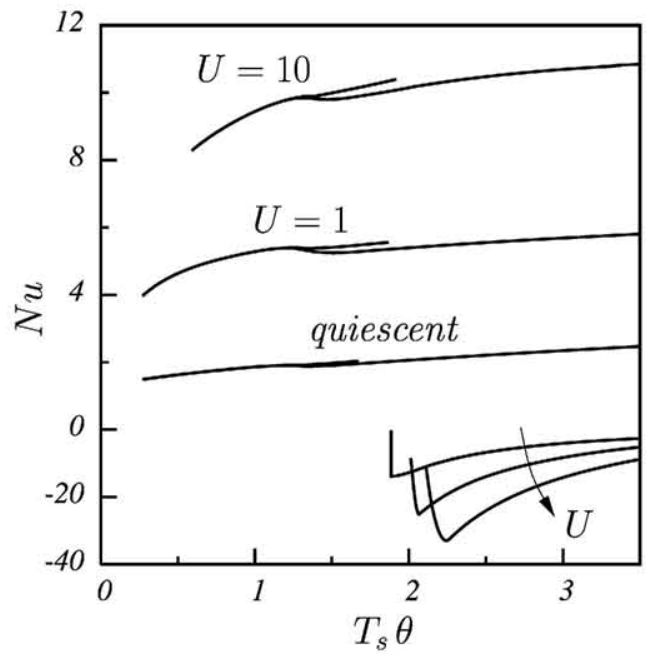

Fig. 2. Nusselt number as a function of the surface temperature scaled with $T_{\infty_{\mathrm{r}}}=1000 \mathrm{~K}$ for $\theta=1.35\left(T_{\infty}=1350 \mathrm{~K}\right)$ and $\alpha=50$ (10-mm particle radius). The three curves in the lower part of the figure are, from top to bottom, for a quiescent particle, for $U=1\left(U_{\infty}=1 \mathrm{~m} / \mathrm{s}\right)$, and for $U=10$ $\left(U_{\infty}=10 \mathrm{~m} / \mathrm{s}\right)$, with a diffusion flame surrounding the particle. The three couples of curves in the upper part of the figure are for cases without $\mathrm{CO}$ flame or with a diffusion flame adjacent to the surface.

A Sherwood number measuring the global mass transfer rate from the particle to the gas can also be computed. When the surface reactions are diffusioncontrolled, the Sherwood number is $\mathrm{Sh}=(8 / 3) \mathrm{ReSc}$ $\times\langle m\rangle / Y_{\mathrm{O}_{2} \infty}$, where $\langle m\rangle$ can be extracted from Fig. 1. The values of the Sherwood number for the highest $T_{\mathrm{S}}$ in Fig. 1a are $\mathrm{Sh}=2.70,6.04$, and 10.96, for a quiescent particle, $U=1$ and 10 , respectively, in the absence of a gas flame (and similar values are obtained for cases with a gas flame). These results are in qualitative agreement with the Marshall-Ranz correlation.

The circumferential distributions of the first two terms on the right-hand side of (16), at the surface of the particle, are shown in Fig. 3 for cases with and without a gas flame. The first term of (16) is proportional to the gasification rate, and the second term is the dimensionless heat conduction flux from the surface to the gas. The first term is smaller than the second but not much smaller, meaning that gasification has an influence on the energy balance at the surface and on the flow around the particle. The heat flux and the gasification flux are maxima at the leading stagnation point. They decrease monotonically with distance along the circumference when the velocity of the particle is small, while they reach a minimum and then increase in the rear part of the particle when its velocity is larger. These differences can be traced to the structure of the flow around the particle.
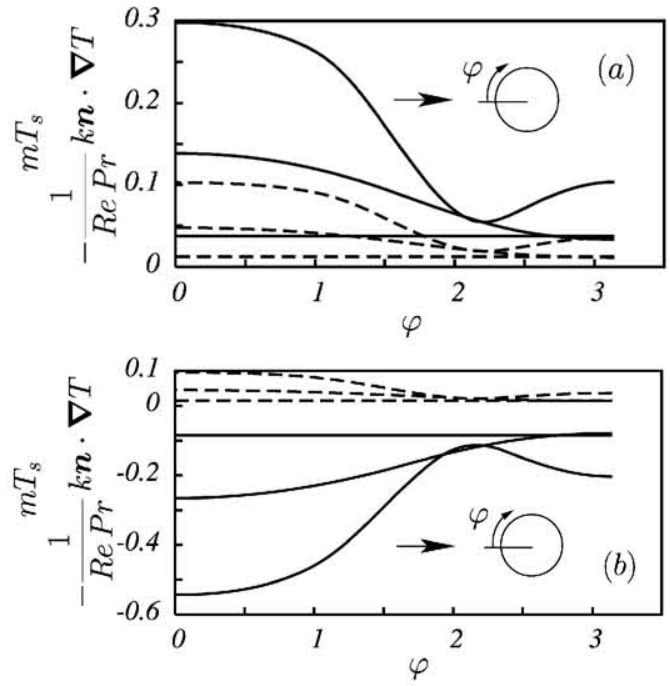

Fig. 3. Circumferential distributions of dimensionless heat conduction flux (-) and $m T_{\mathrm{S}}(--)$ on the surface of a particle for $\theta=1.35, \alpha=50, T_{\mathrm{S}}=2$, and $Y_{\mathrm{O}_{2} \infty}=0.23$. (a) In the absence of gas flame. (b) With a diffusion flame around the particle. The curves shown are for a quiescent particle, for $U=1\left(U_{\infty}=1 \mathrm{~m} / \mathrm{s}\right)$, and for $U=10\left(U_{\infty}=10 \mathrm{~m} / \mathrm{s}\right)$, increasing from bottom to top, except for the three lower curves of (b).

Fig. 4 shows some isotherms and streamlines of the flow for a few selected cases. Figs. $4 \mathrm{a}-4 \mathrm{~d}$ are for cases without a gas flame. The isotherms are nearly spherical in Fig. 4a, for small particle size and velocity, but they become elongated in the direction of the flow, and the dividing streamline approaches the surface, when the velocity or the size of the particle increases (Figs. 4b and 4c). Fig. 4d shows an abrupt separation of the flow at $\operatorname{Re}=318.76$, leading to a large region of relatively intense and cold recirculating flow that extends downstream beyond the boundary of the figure. This recirculating flow impinges on the rear part of the particle and causes the increase of the heat flux and gasification rate seen in Fig. 3. Figs. $4 \mathrm{e}$ and $4 \mathrm{f}$ are for the same particle size and velocities as in Figs. $4 \mathrm{c}$ and $4 \mathrm{~d}$, but with a CO flame present in the gas. As can be seen, the flame is deformed by the flow but does not change much the shape of the streamlines or the general appearance of the isotherms.

Not all the regimes found by assigning an arbitrary value to the surface temperature are easily attainable for a free burning particle, because there are conditions of the gas for which $\left\langle q_{\mathrm{s}}\right\rangle$ in (26) is negative for any $T_{\mathrm{s}}$, meaning that the particle requires a continuous supply of heat to burn under such conditions. In an attempt to rule out these irrealistic cases, computations of the gas-phase flow have been repeated with the surface temperature chosen to satisfy the condi- 

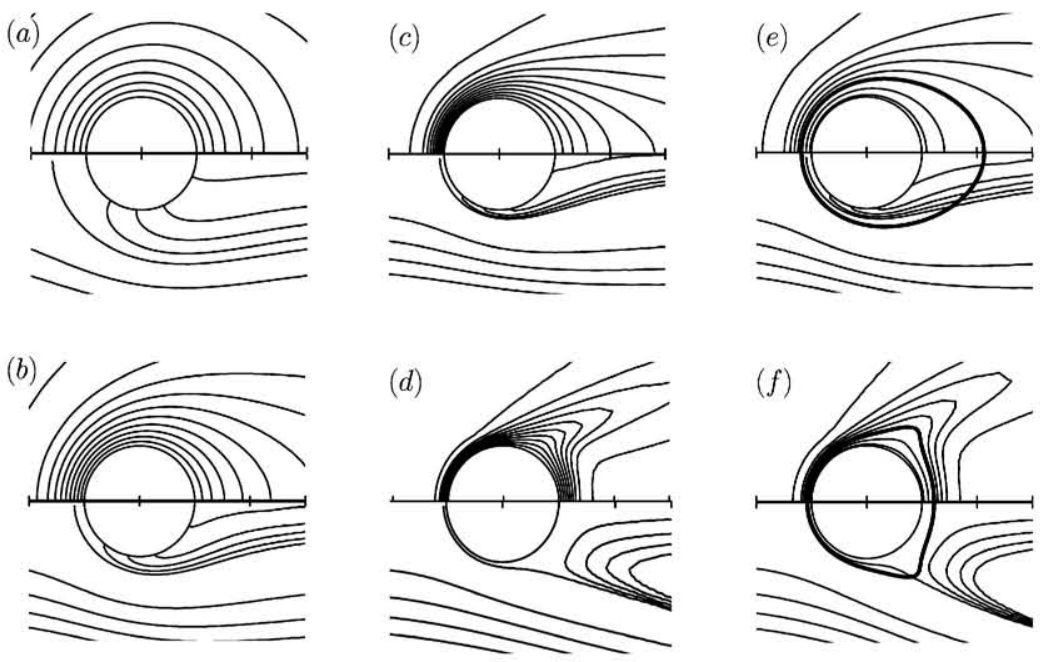

Fig. 4. Isotherms (upper part of each figure) and streamlines of the flow around a particle for $\theta=1.35, T_{\mathrm{S}}=2, Y_{\mathrm{O}_{2} \infty}=0.23$, and (a) $\alpha=1, U=1\left(a=200 \mu \mathrm{m}, U_{\infty}=1 \mathrm{~m} / \mathrm{s}, \operatorname{Re}=0.64\right)$; (b) $\alpha=1, U=10\left(a=200 \mu \mathrm{m}, U_{\infty}=10 \mathrm{~m} / \mathrm{s}, \operatorname{Re}=6.38\right)$; (c) and (e) $\alpha=50, U=1\left(a=10 \mathrm{~mm}, U_{\infty}=1 \mathrm{~m} / \mathrm{s}, \operatorname{Re}=31.88\right)$; and (d) and (f) $\alpha=50, U=10\left(a=10 \mathrm{~mm}, U_{\infty}=10 \mathrm{~m} / \mathrm{s}\right.$, $\operatorname{Re}=318.76$ ). The thick curve in (e) and (f) is the CO flame. No gas flame exists in (a)-(d).

tion

$\left\langle q_{\mathrm{s}}\right\rangle=0$.

As will be seen in Section 3.4 below, numerical computations using Eqs. (25) for the solid show that condition (29) is approximately satisfied during most of the burning process.

Fig. 5a shows the burning rate as a function of the ambient temperature, $\theta$ in (28), for different sizes $(\alpha)$ and velocities $(U)$ of the particle, and different oxygen mass fractions in the free stream. As in Fig. 1, the upper curve of each couple gives the burning rate in the absence of gas flame and the lower curve gives the burning rate when a diffusion-controlled $\mathrm{CO}$ flame exists around the particle or adjacent to its surface. This latter regime is not often realized when condition (29) is imposed. In Fig. 5a it is obtained only in the lowest two curves, which correspond to a particle of radius $a=200 \mu \mathrm{m}$, for which the existence of a CO flame is doubtful anyway

The burning rate in Fig. 5a increases with the ambient temperature $\theta$ in the vicinity of extinction and in a range of moderate values of $\theta$, but the dependence becomes weaker when $\theta$ increases. This result agrees with the experimental findings of Ragland and Yang [16] and reflects the heterogeneous reactions rapidly becoming diffusion-controlled when $\theta$ increases, and the only dependence of $\langle m\rangle$ on $\theta$ being through the temperature variation of the transport coefficients. Results for the diffusion-controlled limit, in which the conditions $Y_{\mathrm{O}_{2}}=Y_{\mathrm{CO}_{2}}=0$ replace the first two equations (17) at the surface, rapidly become indistinguishable from those of Fig. 5a when $\theta$ increases. The results for diffusion-controlled reactions have not been displayed in order not to clutter the figure. Fig. 5a also shows that the burning rate increases with the velocity of the particle, specially for large particles (compare curves 1 and 2 for a particle of radius $a=200 \mu \mathrm{m}$ with curves 3 and 4 for $a=10 \mathrm{~mm}$ ), and with the oxygen mass fraction. The extinction value of $\theta$ below which vigorous burning does not occur slightly increases with the velocity of the particle.

The temperature of the particle, $T_{\mathrm{S}} \theta$, is given in Fig. $5 \mathrm{~b}$ for the cases of Fig. $5 \mathrm{a}$. As can be seen, when $\theta$ increases $T_{\mathrm{S}} \theta$ tends to increase linearly with it and to become independent of the size and velocity of the particle and of the presence of a $\mathrm{CO}$ flame in the gas. The particle temperature branches from this common linear relationship when $\theta$ decreases, with small and fast-moving particles branching earlier. In the absence of a $\mathrm{CO}$ flame, $T_{\mathrm{S}} \theta$ decreases faster than linearly with $\theta$, rapidly leading to extinction. With a $\mathrm{CO}$ flame present, $T_{\mathrm{S}} \theta$ decreases less than linearly because the exothermic flame approaches the surface, and even coincides with it, when $\theta$ decreases. The very high surface temperatures on the right-hand side of Fig. $5 \mathrm{~b}$ are a consequence of neglecting radiative heat transfer.

The shape of the flame sheet is shown in Fig. 6 for a few sample cases. The distance from the flame to the leading part of the surface increases with the ambient temperature and the oxygen mass fraction in the gas $\left(Y_{\mathrm{O}_{2} \infty}\right)$, and decreases when the velocity of the particle increases. The effect of the ambient temperature is to increase the gasification rate; see Fig. 5a. 

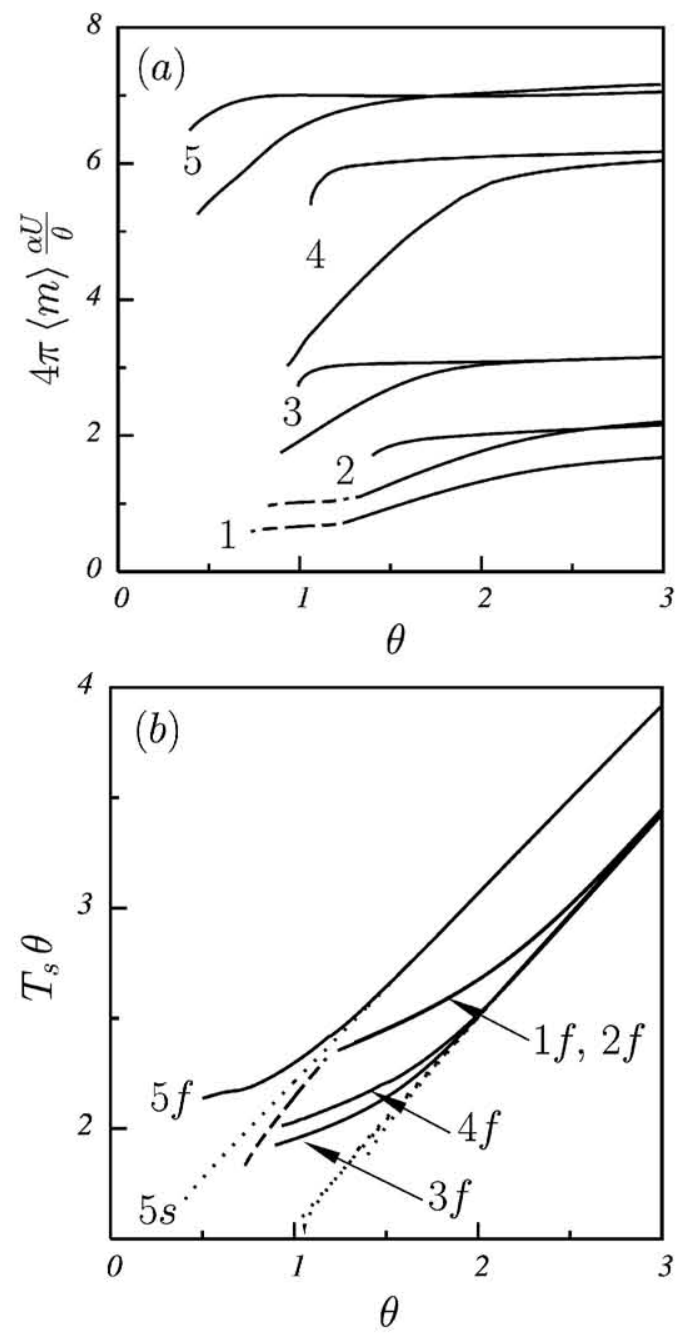

Fig. 5. (a) Burning rate scaled with $\rho_{\infty_{\mathrm{r}}} U_{\infty_{\mathrm{r}}} a_{\mathrm{r}}^{2} \alpha$ as a function of the ambient temperature $\theta$ scaled with $T_{\infty_{\mathrm{r}}}$ for the following sets of parameter values. 1: $\alpha=1, Y_{\mathrm{O}_{2} \infty}=0.1$, $U=1 ; 2: \alpha=1, Y_{\mathrm{O}_{2} \infty}=0.1, U=10 ; 3: \alpha=50$, $Y_{\mathrm{O}_{2} \infty}=0.1, U=1 ; 4: \alpha=50, Y_{\mathrm{O}_{2} \infty}=0.1, U=10$; and 5: $\alpha=50, Y_{\mathrm{O}_{2} \infty}=0.23, U=1$. The upper curve of each couple gives the burning rate in the absence of gas flame. This curve has been omitted in case 1 to avoid cluttering the figure. The dashed segments of curves 1 and 2 are for a CO flame coinciding with the surface of the particle. Because of the factor $\alpha$ introduced in the scaling of the burning rate, this is divided by 50 in cases $3-5$. (b) Surface temperature as a function of the ambient temperature, both scaled with $T_{\infty_{\mathrm{r}}}$, for the same cases of (a). Letter $f$ indicates results with a $\mathrm{CO}$ flame in the gas and letter $s$ results with heterogeneous reactions only.

The effect of $Y_{\mathrm{O}_{2} \infty}$ can be understood noticing that the temperature and the mass fraction of $\mathrm{CO}_{2}$ at the flame increase with $Y_{\mathrm{O}_{2} \infty}$; this increases the fluxes of heat and $\mathrm{CO}_{2}$ reaching the surface of the particle, and

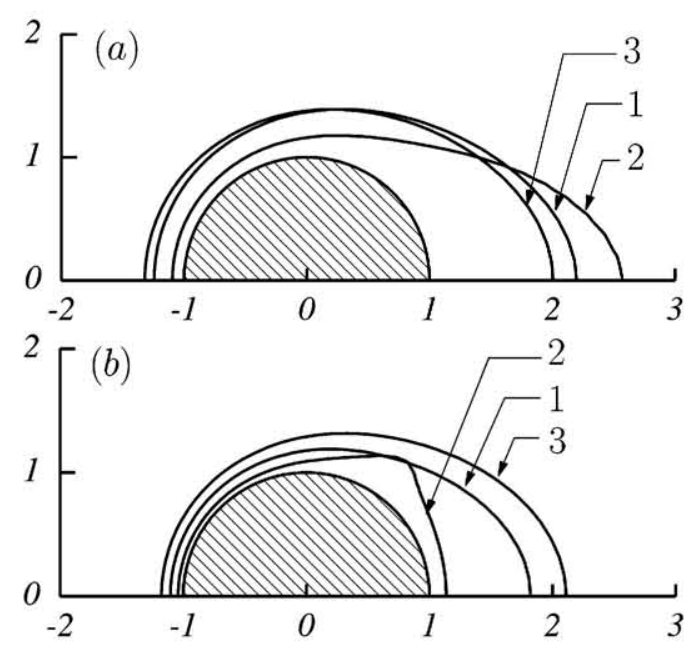

Fig. 6. Flame sheet around a particle for $\alpha=50$ and $\left(Y_{\mathrm{O}_{2} \infty}, U\right)=(0.1,1) \quad($ curve 1$),(0.1,10)$ (curve 2), and $(0.23,1)$ (curve 3$)$. In (a) $\theta=3\left(T_{\infty}=3000 \mathrm{~K}\right)$; in (b) $\theta=1.35\left(T_{\infty}=1350 \mathrm{~K}\right)$.

therefore its temperature and the rate of gasification through the endothermic reaction (1b) (which may be diffusion-controlled). The increased gasification flux pushes the flame away from the surface when either $Y_{\mathrm{O}_{2} \infty}$ or the ambient temperature increases.

The shape of the flame at the rear part of the particle shows a more complex dependence on the conditions of the flow. At high ambient temperatures, of which Fig. 6a is an extreme case, the rearmost point of the flame shifts upstream when $Y_{\mathrm{O}_{2} \infty}$ increases or the velocity of the particle decreases. The feedback between the flame and the surface is weaker here than in the leading part of the particle because the distance between the two is larger. Under these conditions, the upstream shift of the flame with increasing $Y_{\mathrm{O}_{2} \infty}$ reflects the effect of the increased diffusion flux of oxygen toward the flame. At lower ambient temperatures, on the other hand, the rear part of the flame shifts downstream when $Y_{\mathrm{O}_{2} \infty}$ increases (compare flames 1 and 3 in Fig. 6b) and becomes increasingly deformed when the velocity increases. The first result shows that the increase of the total gasification rate with $Y_{\mathrm{O}_{2} \infty}$ (compare curves 3 and 5 in Fig. 5a) overcomes the increased oxygen diffusion flux toward the flame. The effect of the particle velocity can be explained by reference to Fig. $4 \mathrm{f}$. The strong recirculating flow that exists behind the particle when the combination of a high velocity and a moderate ambient temperature leads to a high Reynolds number pushes the flame toward the rear part of the particle.

Leaving aside cases with strong recirculation, the distance from the rearmost point of the flame to the surface (not displayed) first increases with the ambient temperature $\theta$, reaches a maximum at a certain $\theta$, 
and then decreases slightly. The initial increase may be due to the increase of the gasification rate with $\theta$ at moderate values of $\theta$; see Fig. 5a. The final decrease may be due to the increase of the transport coefficients with temperature.

The pressure and viscous forces acting on the surface of the particle, together with the flow of momentum accompanying gasification, lead to a drag that opposes the motion of the particle. In dimensionless variables, the drag scaled with $\rho_{\infty} U_{\infty}^{2} a^{2}$ is given by the integral

$$
D=\int_{|\mathbf{x}|=1}\left\{-\left(p+\frac{m^{2}}{\rho}\right) \mathbf{n}+\tau^{\prime} \cdot \mathbf{n}\right\} \cdot \mathrm{i} d \sigma,
$$

where the term $-(\mathbf{n} \cdot \mathbf{i}) m^{2} / \rho$ is the contribution of the gasification. The dimensionless drag divided by $\theta=T_{\infty} / T_{\infty_{\mathrm{r}}}$ is given in Fig. 7 as a function of the ambient temperature. In Fig. 7a, for particles of radius $a=10 \mathrm{~mm}$, the rescaled drag does not depend much on the ambient temperature, except in the vicinity of extinction, and decreases when the velocity of the particle increases (though the dimensional drag increases with velocity). For given values of the parameters, the drag is little affected by the presence of a $\mathrm{CO}$ flame in the gas. The largest effect of the flame occurs for $Y_{\mathrm{O}_{2} \infty}=0.23$ (solid curves), for which its presence causes a slight decrease of the drag. Larger values of the dimensionless drag and of its sensitivity to the ambient temperature and to the velocity of the particle are found for small particles; see Fig. 7b for $a=200 \mu \mathrm{m}$, where only cases without gas flame have been included, as the existence of a flame around these small particles is doubtful. In summary, and in agreement with expected tendencies, the results show a larger influence of the Reynolds number (of the viscosity and its variation with temperature) on the dimensionless drag in the cases of Fig. 7b, for which $\mathrm{Re}$ is of order unity or small, than in the cases of Fig. 7a, for which Re ranges from about 10 to somewhat above 500 .

\subsection{Cases with heterogeneous reactions only}

The influence of the size and velocity of the particle on the surface-averaged gasification rate (see (26)) and particle temperature in the vicinity of extinction is illustrated in Fig. 8 for small particles without gas flame. (Only genuine extinctions are considered; quasi-extinction events depending on a transition from zone II to zone I combustion are beyond the scope of the model used here.) The solid curves in Fig. 8 are for quiescent particles and show the well known increase of the extinction temperature when the size of the particle decreases. This is due to
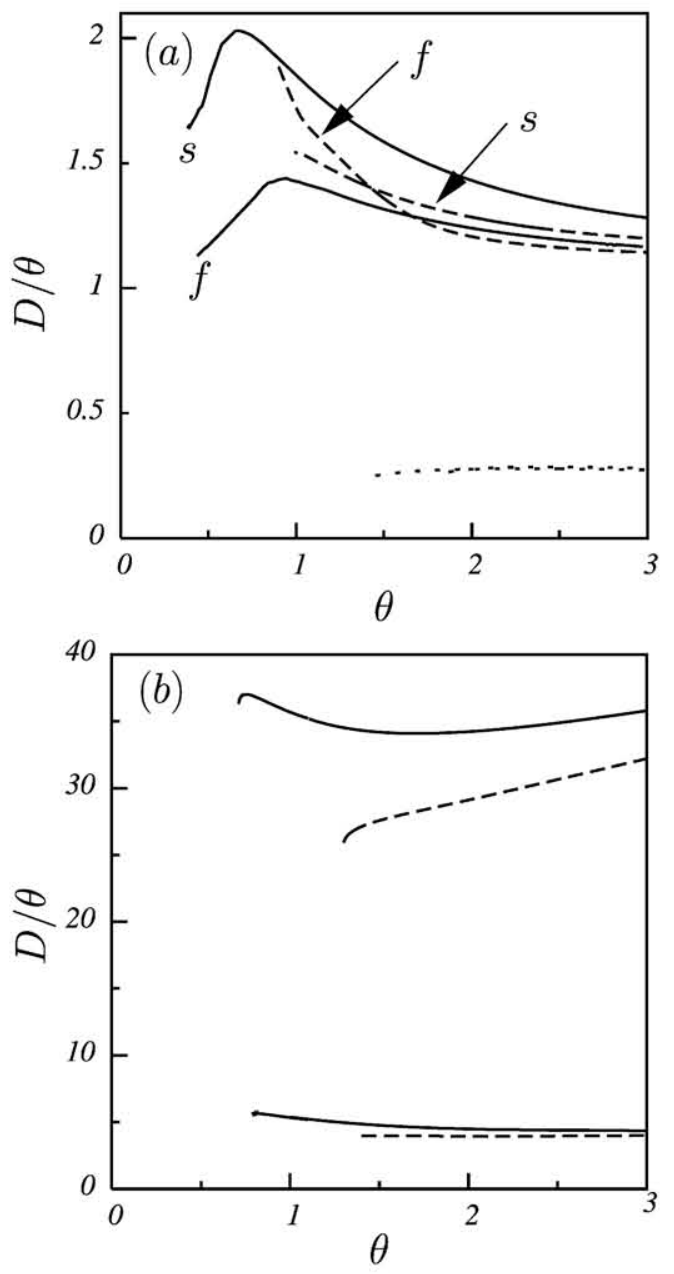

Fig. 7. Drag of a particle scaled with $\rho_{\infty} U_{\infty}^{2} a^{2} \theta$ as a function of the ambient temperature scaled with $T_{\infty_{\mathrm{r}}}$. In (a) $\alpha=50$ and $\left(Y_{\mathrm{O}_{2} \infty}, U\right)=(0.23,1)(-),(0.1,1)(--)$, and $(0.1,10)(\cdots)$. Letter $f$ indicates results with a CO flame in the gas and letter $s$ results with heterogeneous reactions only. Both results are indistinguishable for the dotted curves in the lower part of the figure. In (b), for $\alpha=1$ and heterogeneous reactions only, $\left(Y_{\mathrm{O}_{2} \infty}, U\right)=(0.23,1)$ (upper solid), $(0.23,10)$ (lower solid), $(0.1,1)$ (upper dashed), and $(0.1,10)$ (lower dashed).

the decrease of the diffusion time and the Damköhler number with the size of the particle, so that higher ambient temperatures are required to keep the surface reaction going for small particles than for large particles. The motion of the particle increases both the gasification rate and the extinction temperature, but these effects are felt only when the Reynolds number of the flow around the particle ceases to be small, which requires higher velocities for small particles than for large particles. Thus the solid and dashed curves of Fig. 8, for a quiescent particle and for 

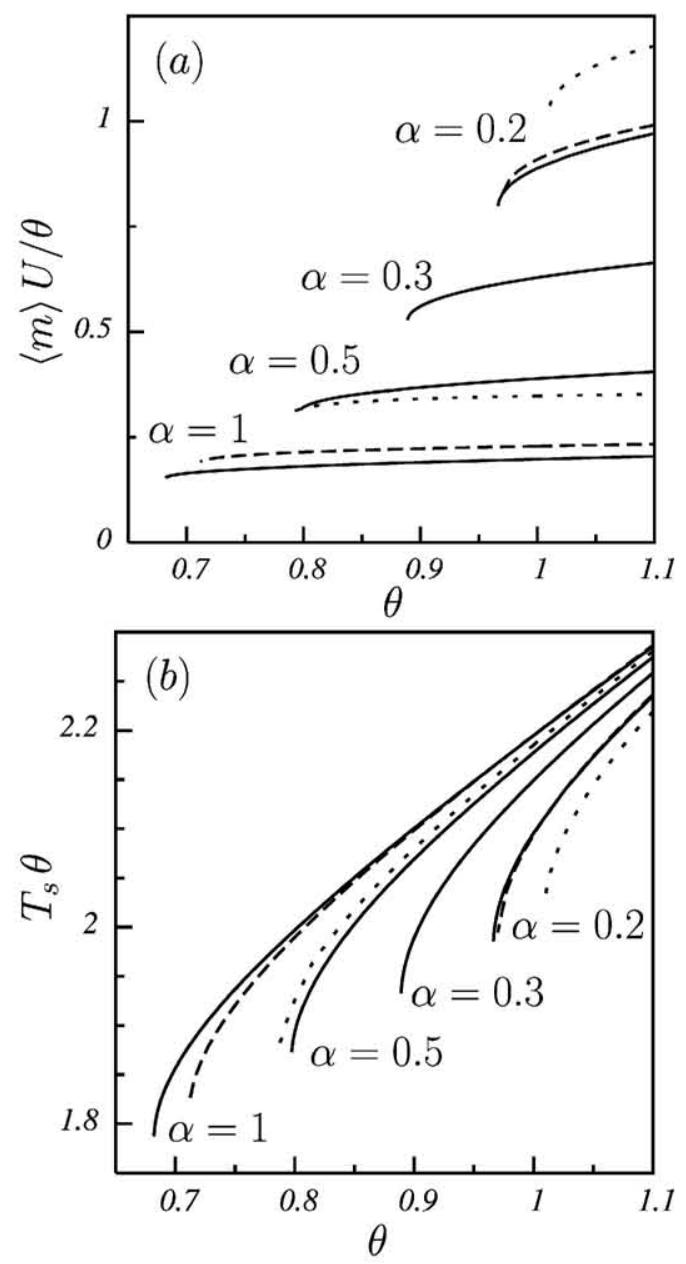

Fig. 8. (a) Surface-averaged gasification rate scaled with $\rho_{\infty_{\mathrm{r}}} U_{\infty_{\mathrm{r}}}=0.273 \mathrm{~kg} /\left(\mathrm{m}^{2} \mathrm{~s}\right)$ as a function of the ambient temperature scaled with $T_{\infty_{\mathrm{r}}}=1000 \mathrm{~K}$. (b) Surface temperature as a function of the ambient temperature, both scaled with $T_{\infty_{\mathrm{r}}}$, for $Y_{\mathrm{O}_{2} \infty}=0.23, Y_{\mathrm{CO}_{2} \infty}=0$, and several values of $\alpha$. (-) are for a quiescent particle, (--) for $U=1$, and $(\cdots)$ for $U=10 .(--)$ and $(\cdots)$ are shown only for the two extreme cases $\alpha=0.2$ and 1 .

$U=1$, respectively, nearly coincide with each other for the smallest particles but are clearly distinguishable for the largest particles. A velocity of $10 \mathrm{~m} / \mathrm{s}$ would be required for the flow to have a noticeable effect on a particle of radius $40 \mu \mathrm{m}$, but such a combination of high velocity and small particle size is not realistic.

Under many conditions of interest for pulverized coal combustion, the oxidation of $\mathrm{CO}$ to $\mathrm{CO}_{2}$ occurs in a large scale flame collectively fed by many gasifying particles. Individual particles move in a gas containing $\mathrm{O}_{2}$ and $\mathrm{CO}_{2}$, among other species, and undergo only heterogeneous reactions at their surfaces. The mass fraction of $\mathrm{CO}_{2}$ in the gas may be large for
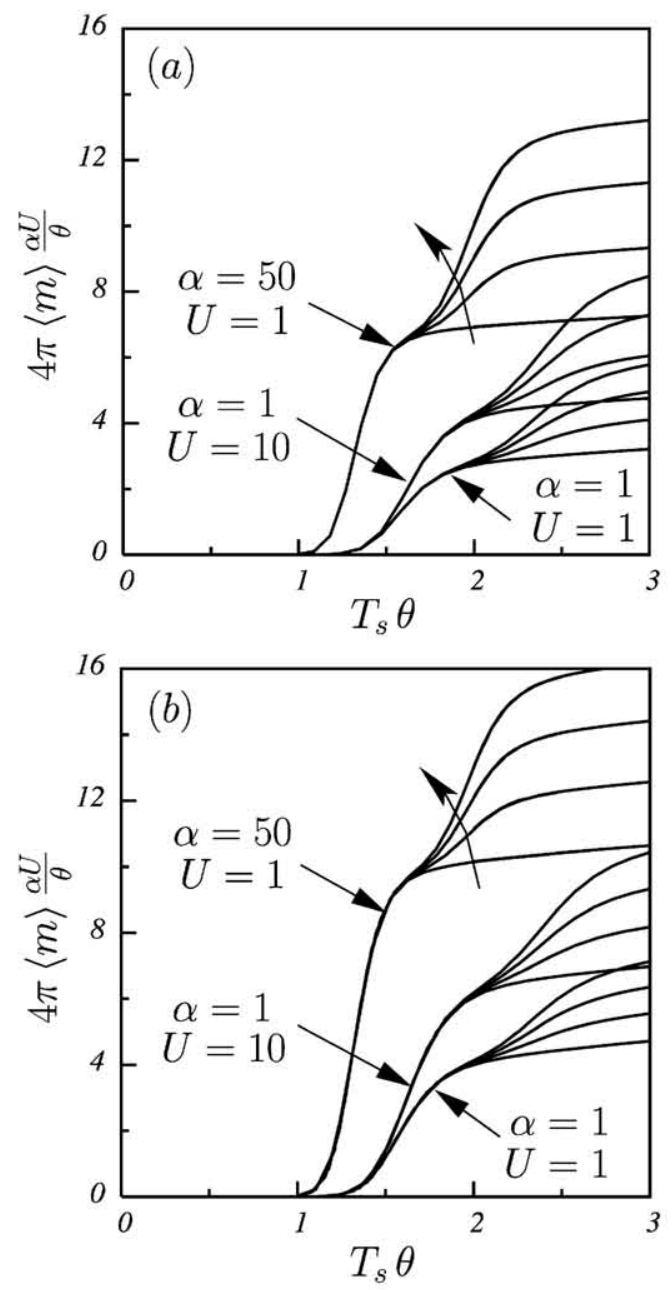

Fig. 9. Gasification rate scaled with $\rho_{\infty_{\mathrm{r}}} U_{\infty_{\mathrm{r}}} a_{\mathrm{r}}^{2} \alpha$ as a function of the surface temperature scaled with $T_{\infty_{\mathrm{r}}}$, for $\theta=1$ $\left(T_{\infty}=1000 \mathrm{~K}\right), Y_{\mathrm{O}_{2} \infty}=0.23$ (in (a)) and 0.35 (in (b)), and various values of $\alpha$ and $U$. The four curves of each set are for $Y_{\mathrm{CO}_{2} \infty}=0,0.2,0.4$, and 0.6 , increasing from bottom to top as indicated by the curved arrows.

applications of oxy-fuel combustion with $\mathrm{CO}_{2}$ recycling, for which the reactions (1a) and (1b) operate in tandem. The gasification rate of a particle under these conditions is given in Fig. 9 as a function of the particle temperature for different values of its radius and velocity and of the mass fractions of $\mathrm{O}_{2}$ and $\mathrm{CO}_{2}$ in the gas. The two steps of the curves reflect the consecutive transitions of reactions (1a) and (1b) from frozen to diffusion-controlled. The second reaction comes into play only at high temperatures, due to its high activation temperature, leading to the branching of the curves for different $\mathrm{CO}_{2}$ mass fractions from a common curve at low temperatures, when only reaction (1a) is active. The gasification rate increases with the 
size and velocity of the particle. The ratio of the gasification rate of a moving particle to its value when the particle is at rest increases, and the second step of the curves shifts to lower temperatures, when the size of the particle increases. Since the $\mathrm{CO}_{2}$ reaction (1b) is endothermic, not all the diagrams of the type of Fig. 9 give states that are easily attainable for a free particle, for the reasons already mentioned in connection with Fig. 1. Thus, although results for $Y_{\mathrm{O}_{2} \infty}=0.1$ have the same general appearance as those in Fig. 9 (except for a lower first step), an energy balance reveals that energy should always be supplied from outside because the heat released by the $\mathrm{O}_{2}$ reaction (1a) is not sufficient to make up for the heat absorbed by the $\mathrm{CO}_{2}$ reaction (1b) and the particle conductive losses in an atmosphere at $T_{\infty}=1000 \mathrm{~K}$.

The gasification rate determined using condition (29) instead of assigning an arbitrary value to the surface temperature, is shown in Fig. 10. As in Fig. 5a, the gasification rate increases with the size and velocity of the particle and with the mass fraction of oxygen in the gas, and reaction (1a) rapidly becomes diffusion-controlled when the temperature increases. At high temperatures, the gasification rate also increases with the mass fraction of carbon dioxide, but the effect of this variable decreases when the ambient temperature decreases. In particular, the extinction conditions are in most cases independent of the mass fraction of $\mathrm{CO}_{2}$. The temperature of the particle (not displayed) increases with the ambient temperature of the gas, decreases with the mass fraction of $\mathrm{CO}_{2}$, and is nearly independent of the size and velocity of the particle.

\subsection{Time evolution of the particle radius and temperature}

Once the gasification rate is known as a function of the conditions of the gas and the size and temperature of the particle, Eqs. (25) can be used to find the time evolution of the particle radius and temperature. These equations have been solved with the initial conditions $\bar{a}=1$ and $T_{\mathrm{S}}$ set to satisfy (29) at the initial time. Solutions for different, constant conditions of the gas are shown in Figs. 11 (dimensionless radius) and 12 (dimensionless temperature). Only cases without $\mathrm{CO}$ gas flame are considered, and the common dimensionless time $\bar{\tau}=\rho_{\infty_{\mathrm{r}}} U_{\infty_{\mathrm{r}}} t / \rho_{\mathrm{S}} a_{0}=$ $\tau \theta / U$ (cf. (28)) is used to compare solutions for different velocities and ambient temperatures. In all the cases computed, the temperature of the particle is nearly constant and the square of its radius decreases nearly linearly with time during most of the gasification process, which reflects diffusion-controlled heterogeneous reactions. At low ambient temperatures $\left(T_{\infty}=1000 \mathrm{~K}\right.$, Figs. 11a and 12a), the en-
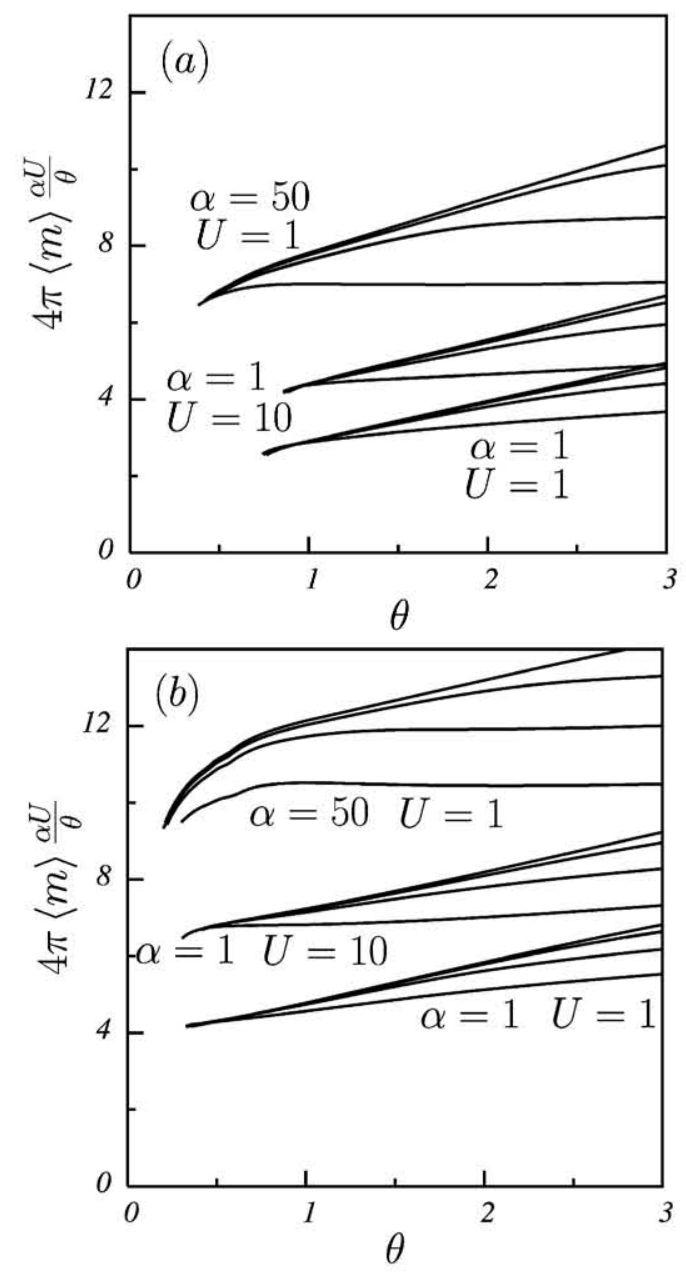

Fig. 10. Gasification rate scaled with $\rho_{\infty_{\mathrm{r}}} U_{\infty_{\mathrm{r}}} a_{\mathrm{r}}^{2} \alpha$ as a function of the ambient temperature scaled with $T_{\infty_{\mathrm{r}}}$, for $Y_{\mathrm{O}_{2} \infty}=0.23$ (in (a)) and 0.35 (in (b)), and various values of $\alpha$ and $U$. The four curves of each set are for $Y_{\mathrm{CO}_{2} \infty}=0$, $0.2,0.4$, and 0.6 , increasing from bottom to top.

dothermic $\mathrm{CO}_{2}$ reaction contributes little to the gasification when $Y_{\mathrm{O}_{2} \infty}=0.23$, but it still reduces the temperature of the particle and precipitates extinction, especially at high particle velocities; see the two couples of curves in the lower part of Fig. 12a and the nearly indistinguishable curves of the two upper couples in Fig. 11a. The effect of the $\mathrm{CO}_{2}$ reaction is slightly larger for $Y_{\mathrm{O}_{2} \infty}=0.35$ (lower couple of curves in Fig. 11a), leading to a gasification rate that increases with the concentration of $\mathrm{CO}_{2}$ in the gas. The particle temperature is higher (upper couple of curves in Fig. 12a) and the gasification is faster than when $Y_{\mathrm{O}_{2} \infty}=0.23$. In addition, the rate of the $\mathrm{CO}_{2}$ reaction (1b) declines now slightly before the final extinction, leading to a rise of the particle temperature immediately before its fi- 

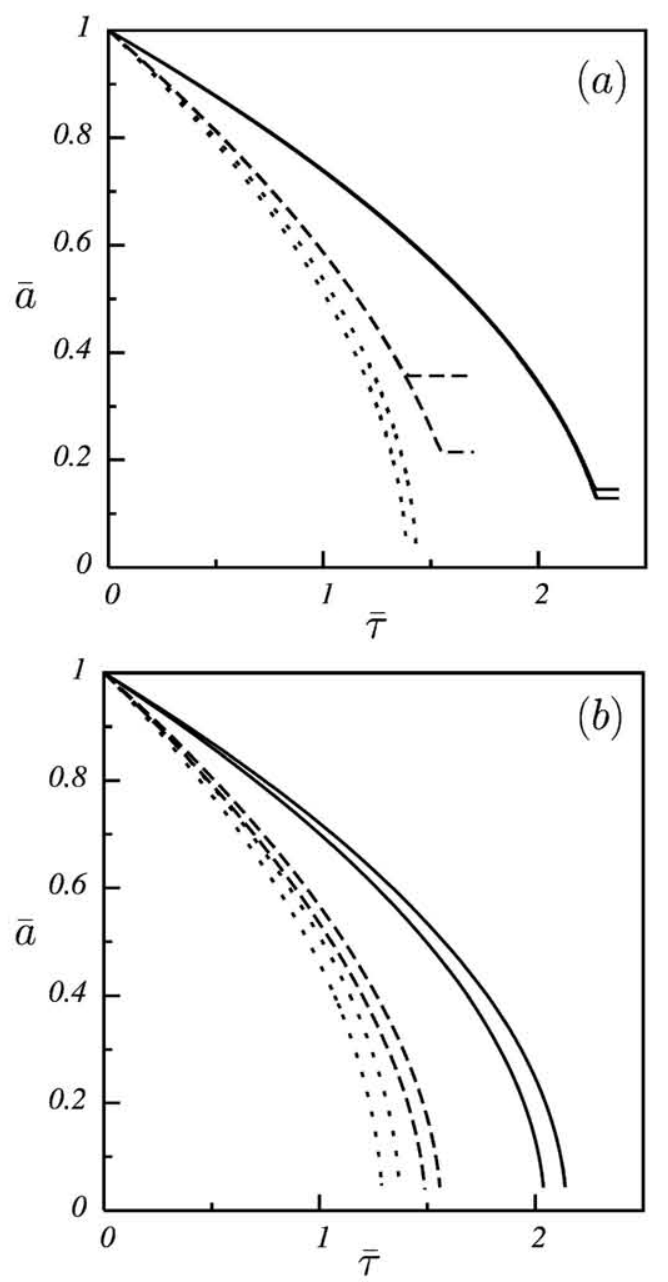

Fig. 11. Radius of the particle scaled with its initial value $a_{0}=a_{\mathrm{r}}=200 \mu \mathrm{m}$ as a function of time scaled with $\left(\rho_{\mathrm{s}} / \rho_{\infty_{\mathrm{r}}}\right) a_{0} / U_{\infty_{\mathrm{r}}}$ for $\theta=1$ (a) and 1.35 (b), and $\left(Y_{\mathrm{O}_{2} \infty}, U\right)=(0.23,1)(-),(0.23,10)(--)$, and $(0.35,1)$ $(\cdots)$. The upper curve of each couple is for $Y_{\mathrm{CO}_{2} \infty}=0$ and the lower curve for $Y_{\mathrm{CO}_{2} \infty}=0.4$.

nal fall (Fig. 12a). At higher ambient temperatures $\left(T_{\infty}=1350 \mathrm{~K}\right.$, Figs. $11 \mathrm{~b}$ and $\left.12 \mathrm{~b}\right)$, the presence of $\mathrm{CO}_{2}$ in the gas increases the gasification rate and induces a rise and fall of the particle temperature at the end of the process for any value of the oxygen mass fraction. The size of the unburnt particles left when extinction occurs decreases when the ambient temperature increases, whereas the total gasification time decreases only slightly.

The results of this section change very little when the second equation (25) is replaced by (29). This shows that the thermal inertia of the particle does not play an important role in the gasification process, at least if condition (29) is fulfilled initially, and justifies the use of this condition in the previous sections.
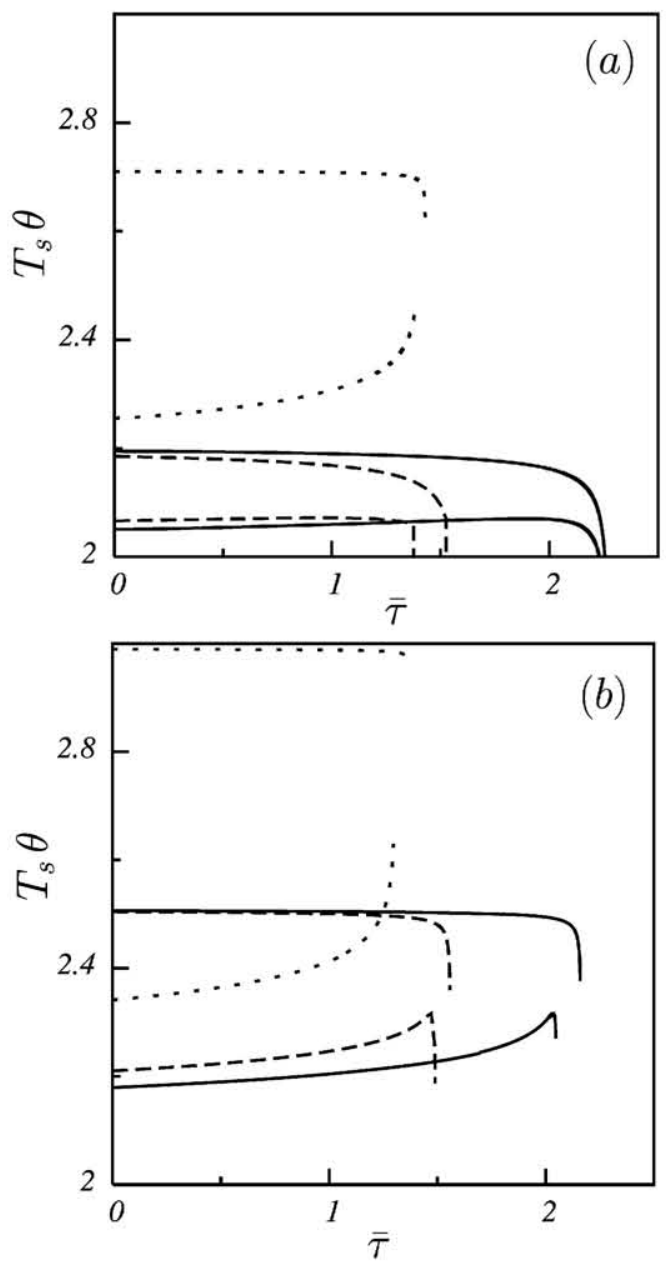

Fig. 12. Surface temperature scaled with $T_{\infty_{\mathrm{r}}}$ as a function of time scaled with $\left(\rho_{\mathrm{S}} / \rho_{\infty_{\mathrm{r}}}\right) a_{0} / U_{\infty_{\mathrm{r}}}$ for $\theta=1$ (a) and 1.35 (b), and $\left(Y_{\mathrm{O}_{2} \infty}, U\right)=(0.23,1)(-),(0.23,10)(--)$, and $(0.35,1)(\cdots)$. The upper curve of each couple is for $Y_{\mathrm{CO}_{2} \infty}=0$ and the lower curve for $Y_{\mathrm{CO}_{2} \infty}=0.4$.

\section{Conclusions}

The effect of the motion of a burning coal particle relative to the surrounding gas has been investigated numerically, taking into account the heterogeneous reactions $\mathrm{C}+(1 / 2) \mathrm{O}_{2} \rightarrow \mathrm{CO}$ and $\mathrm{C}+\mathrm{CO}_{2} \rightarrow 2 \mathrm{CO}$ at the surface of the particle and the gas-phase reaction $\mathrm{CO}+(1 / 2) \mathrm{O}_{2} \rightarrow \mathrm{CO}_{2}$ in cases where $\mathrm{CO}$ oxidation occurs in a diffusion flame around the particle. Arrhenius kinetics is assumed for the heterogeneous reactions and the gas-phase reaction is taken to be infinitely fast when it occurs. Particle radii in the range $40 \mu \mathrm{m}-10 \mathrm{~mm}$ and particle velocities in the range $0-10 \mathrm{~m} / \mathrm{s}$ have been considered. Depending on the ambient temperature, this leads to Reynolds 
numbers of the particle-to-gas relative motion up to about 1000 .

The burning rate increases with the velocity of the particle due to the flow-enhanced transfer of reactants between the gas and the surface. The temperature of the particle is nearly independent of its size and velocity, except in the vicinity of extinction, and increases with the temperature and oxygen concentration of the gas. The extinction temperature increases with the velocity of the particle when the Reynolds number of the relative flow is not small, and decreases when the size of the particle increases.

When a CO flame surrounds the particle, the distance from the flame to the leading part of the surface increases with the ambient temperature and oxygen mass fraction, and decreases with the velocity of the particle. The shape of the flame in the rear part of the particle and its elongation in the streamwise direction show a more complex dependence on these parameters, reflecting the changes of the flow pattern in the wake of the particle.

The drag coefficient of a burning particle is a decreasing function of the particle size and velocity, owing to the effect of these parameters on the Reynolds number, and depends little on the presence of a CO flame around the particle.

The presence of $\mathrm{CO}_{2}$ in the gas around a small particle has an important effect at high gas temperature, for which the endothermic high activation energy heterogeneous reaction $\mathrm{C}+\mathrm{CO}_{2} \rightarrow 2 \mathrm{CO}$ increases the gasification rate and decreases the particle temperature. The minimum ambient temperature at which this reaction comes into play decreases when the size of the particle increases.

Time histories of the size and temperature of small gasifying particles show that the gasification time and the size of the particle at extinction decrease when the ambient temperature and oxygen mass fraction increase. The particle temperature changes little during most of the process and the thermal inertia of the particle does not play an important role.

\section{References}

M.A. Field, Combust. Flame 14 (1970) 237-248.

I.W. Smith, Combust. Flame 17 (1971) 303-314.

R.H. Hurt, J.-K. Sun, M. Lunden, Combust. Flame 113 (1998) 181-197.
R.E. Mitchell, Proc. Combust. Inst. 28 (2000) 22612270 .

J.-K. Sun, R.H. Hurt, S. Niksa, L. Muzio, A. Mehta, J. Stallings, Combust. Sci. Technol. 175 (2003) 10851108.

R.H. Hurt, J.M. Calo, Combust. Flame 125 (2001) 1138-1149.

R.H. Hurt, B.S. Haynes, Proc. Combust. Inst. 30 (2005) 2161-2168.

J. Ballester, S. Jiménez, Combust. Flame 142 (2005) 210-222.

J.J. Murphy, C.R. Shaddix, Combust. Flame 144 (2006) 710-729.

R.K. Chakraborty, J.R. Howard, J. Inst. Fuel 51 (1978) 220-224.

K.W. Ragland, T.C. Jehn, J.-T. Yang, Proc. Combust. Inst. 18 (1981) 1295-1303.

R.D. LaNauze, K. Jung, Proc. Combust. Inst. 19 (1983) 1087-1092.

R.K. Chakraborty, J.R. Howard, J. Inst. Energy 54 (1981) 48-54.

R.H. Essenhigh, J. Eng. Power 85 (1963) 183-190.

R.H. Essenhigh, G.C. Yorke, Fuel 44 (1965) 177-189.

K.W. Ragland, J.-T. Yang, Combust. Flame 60 (1985) 285-297.

K. Annamalai, W. Ryan, Prog. Energy Combust. Sci. 19 (1993) 383-446.

K. Matsui, A. Koyama, K. Uehada, Combust. Flame 25 (1975) 57-66.

K. Matsui, H. Tsuji, A. Makino, Combust. Flame 50 (1983) 107-118.

K. Matsui, H. Tsuji, A. Makino, Carbon 21 (1983)320321 .

K. Matsui, H. Tsuji, A. Makino, Combust. Flame 63 (1986) 415-427.

K. Matsui, H. Tsuji, Combust. Flame 70 (1987) 79-99. K. Matsui, H. Tsuji, Combust. Flame 81 (1990) 86-92. G. Adomeit, G. Mohiuddin, N. Peters, Proc. Combust. Inst. 16 (1976) 731-743.

G. Adomeit, W. Hocks, K. Henriksen, Combust. Flame 59 (1985) 273-288.

K. Henriksen, W. Hocks, G. Adomeit, Combust. Flame 71 (1988) 169-177.

J.B. Howard, G.C. Williams, D.M. Fine, Proc. Combust. Inst. 14 (1973) 975-986.

T.R. Blake, P.A. Libby, Combust. Flame 86 (1991) 147-161.

P.A. Libby, T.R. Blake, Combust. Flame 36 (1979) 139-169.

P.A. Libby, Combust. Flame 38 (1980) 285-300.

P.A. Libby, T.R. Blake, Combust. Flame 41 (1981) 123-147.

E.R. Monazam, D.J. Maloney, Combust. Flame 99 (1994) 733-741.

S.P. Musarra, T.H. Fletcher, S. Niksa, H.A. Dwyer, Combust. Sci. Technol. 45 (1986) 289-307.

M.A. Field, D.W. Gill, B.B. Morgan, P.G.W. Hawksley, Combustion of Pulverized Coal, The British Coal Utilization Research Association, Leatherhead, UK, 1967. E. Mon, N.R. Amundson, Ind. Eng. Chem. Fund. 17 (1978) 313-321. 
M.Y. Ha, B.R. Choi, Combust. Flame 97 (1994) 1-16. A. Makino, C.K. Law, Proc. Combust. Inst. 21 (1986) 183-191.

A. Makino, Combust. Flame 90 (1992) 143-154.

W. Kays, M. Crawford, Convective Heat and Mass Transfer, fourth ed., McGraw-Hill, New York, 2005.
R.E. Mitchell, R.J. Kee, P. Glarborg, M.E. Coltrin, Proc. Combust. Inst. 23 (1990) 1169-1176.

R.H. Essenhigh, H.E. Klimesh, D. Förtsch, Energy Fuels 13 (1999) 826-831.

J.-K. Sun, R.H. Hurt, Proc. Combust. Inst. 28 (2000) 2205-2213. 